\title{
Symptoms of Common Mental Disorders in Brazilian Parents During the COVID-19 Pandemic: Associated Factors
}

\author{
Helena da Silveira Riter ${ }^{1}$ (D) Maíra Lopes Almeida ${ }^{1}$ (D) Gabriela Vescovi ${ }^{1}$ (1)

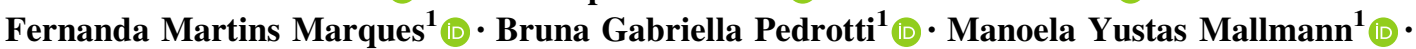 \\ Maria Adélia Minghelli Pieta ${ }^{1}$ (D) Giana Bitencourt Frizzo ${ }^{1}$ (I)
}

Received: 13 August 2020/Accepted: 1 June 2021/Published online: 27 July 2021

(C) National Academy of Psychology (NAOP) India 2021

\begin{abstract}
COVID-19 pandemic has become a significant international public health problem. In addition to dealing with the pandemic's impact on mental health, parents need to cope with specific changes in their routines caused by social distance measures. This study aimed to investigate common mental disorders (CMD) symptoms in Brazilian parents during the COVID-19 pandemic and its associated factors. A total of 232 Brazilian parents ranging from 20 to 48 years old $(M=33.85 ; \mathrm{SD}=4.83)$ with children aged $1-36$ months $(M=17.00 ; \mathrm{SD}=9,87)$ participated in an online survey. Parents answered a sociodemographic questionnaire, Self-Report Questionnaire (SRQ-20), Perceived Stress Scale (PSS-4), and Parenting Sense of Competence Scale. Chi-square tests, correlations, and multiple linear regression were performed. Results showed that parents' symptoms of CMD were negatively associated to perceived parental competence $(\beta=-0.130 ; p=0.011)$ and family income ( $\beta=-0.190 ; p=0.024)$. Furthermore, perceived stress was the most related variable to parents' symptoms of $\mathrm{CMD}(\beta=0.618 ; p<0.001)$, showing a positive association. The model explained $49.5 \%$ of the variation. Results suggest that lower family income may increase symptoms of CMD in Brazilian parents, which is a concern in a country of high social inequality. Parental sense of competence may be a relevant protective factor. Interventions targeting parental competence and stress reduction should be considered to address the mental health impacts of the pandemic.
\end{abstract}

Helena da Silveira Riter

helenariter@gmail.com

1 Psychology Institute, Universidade Federal Do Rio Grande Do Sul, Ramiro Barcelos Street, 2600/112, Porto Alegre, Rio Grande Do Sul (RS) CEP - 90035003, Brazil
Keywords Parents - Mental health - COVID-19 . Common mental disorders - Parental competence . Pandemic

Mathematics Subject Classification I10.

\section{Background}

The new Coronavirus (COVID-19) pandemic has become a significant international public health problem (Holmes et al., 2020; World Health Organization [WHO], 2020a). According to the WHO report (2020b), 17,660,523 people were infected and 680,894 died from COVID-19 over the world up until August 2. Brazil is one of the most affected countries around the globe, with 2,733,677 confirmed cases and 94,104 deaths up until August 2 (Brasil, 2020a).

It is known from previous studies that a pandemic outbreak can cause important psychological effects, such as stress, depression, anxiety, fear and uncertainty that can last even after the pandemic is over (Brooks et al., 2020; Ornell et al., 2020; Wang et al., 2020). In addition to concerns about the population's physical health and the necessary measures to contain the virus, studies focusing on mental health are extremely required (Ornell et al., 2020).

Furthermore, some recent studies have been investigating the possible effects of the COVID-19 pandemic on mental health (Bao et al., 2020; Zhang et al., 2020). Wang et al. (2020) found moderate to severe levels of depression, stress, and anxiety in the Chinese population two weeks after the beginning of the disease. In a rapid review, Brooks et al. (2020) identified that the majority of investigated studies found post-traumatic stress symptoms, anger, and confusion due to quarantine and its associated factors, like 
income problems and fear of infection. A Brazilian study also investigated the symptoms of mental health disorders associated with factors like social distance and family income. The results showed that participants in the risk group for COVID-19 (people over 60 years, diabetics, hypertensive, cardiac and/or breathing problems and pregnant women) or that experienced a decrease in family income were more likely to show symptoms of common mental disorders (anxiety and depression) (Duarte et al., 2020).

Besides the challenges and difficulties faced by all populations, it is important to address specificities regarding parents' mental health. Health emergency situations, such as a disease outbreak can be detrimental to family relations and increase risks in this group (Chung et al., 2020). In addition to dealing with the pandemic's impact on mental health, parents need to cope with specific changes in their routines caused by social distance measures, which can often mean loss of support network, an overload of functions, financial restrictions, and management of children's emotions (Cluver et al., 2020).

A study conducted during a disease epidemic in Australia has already verified that families with one child had a higher risk of psychological distress than those with no children (Taylor et al., 2008). In a sample of Chinese parents, those caring for children under three years old during the COVID-19 outbreak had worse mental health scores (Bai et al., 2020). Yuan et al. (2020) also found higher scores of depression and anxiety in parents compared to peers before the pandemic.

The quality of parent-infant relationships has important implications for child development (Bowlby, 1989; Stern, 1997) since these first relationships will establish the foundations of mental health in the individual (Winnicott, 1987/2006). In this sense, parental mental health is a known factor of relevance to child development and attachment (Bowlby, 1989), especially in early childhood. Difficulties in parents' mental health are linked to delays in child development (Kingston \& Tough, 2014) and reduced quality in early interactions (Parfitt et al., 2013), which have important emotional implications. Factors that can interfere with mental health in a context like the current are the decrease in family income (Duarte et al., 2020; Lebel et al., 2020; Wu et al., 2020), preoccupations related to economy and work (American Psychological Association [APA], 2020a), besides worries about the impact of the coronavirus pandemic on child's social development (APA, 2020b).

Parental stress is extensively investigated in the literature and plays an important role in parenting performance. In this sense, the Center on the Developing Child at Harvard University $(\mathrm{CDCH}, 2017)$ is emphatic concerning the need that public policies should focus on reducing sources of stress in families with children. Parental stress concerns the parents' responses and resources related to situations and demands required in the exercise of parental function (Holly et al., 2019). A study conducted by The Harris Poll (APA, 2020a) in the USA from an online survey with 3.013 adults found that American parents are, on average, feeling significantly higher levels of stress than adults without children during the COVID-19 pandemic. They also identified some sources for parental stress reported by parents, such as a family member getting coronavirus $(74 \%)$, disrupted routines/adjusting to new routines (74\%), getting coronavirus $(73 \%)$, managing distance/online learning for their child(ren) (71\%), self-isolation (67\%), among others (APA, 2020a).

On the other hand, isolation can be an opportunity for an increase in family interaction. This opens a window to moments of proximity and creativity in household activities (Bartlett et al., 2020; Weaver \& Wiener, 2020). Thus, the situation of social distance can bring parents and children closer, allow parents to deepen their relations, and be present to support children's needs (Bartlett et al., 2020). A recent study conducted with parents in the USA found positive perceptions about family relationships due to social distance measures. Results showed, for example, that fathers felt closer to their children, sharing pleasant moments and feelings than before the confinement (Weissbourd et al., 2020).

According to the literature, perceived parental competence is a factor that is related to parental satisfaction, which is essential to child well-being and can contribute to healthy family relations (Matias et al., 2017). In this sense, perceived parental competence refers to parent's perception (Pardo et al., 2018) and expectations of their own role as parents (Ferreira et al., 2014). Studies showed that greater perceived parental competence is positively associated with positive parental practices (Dekovic et al., 2010; Tristão et al., 2015), better mother-infant interaction (Chung et al., 2018) and child well-being (Nunes \& Ayala Nunes, 2016). Contrarily, less perceived parental competence is related to higher scores of depression (Chung et al., 2018), more parental stress (Löfgren et al., 2017), and problematic family function (Laifer et al., 2019).

A Brazilian study investigating the Zika virus epidemic assessed the mediating role of parental self-efficacy related to socio-environmental factors and maternal mental health. Participants were 69 mothers of children diagnosed with Zika Virus Congenital Syndrome. Results suggested that parental self-efficacy predicted better scores of general health and mediated the relation between life satisfaction, negative feelings, and maternal mental health (Lima \& Souza, 2019).

Investigating these variables can help to understand the effects that the pandemic potentially has on parental mental 
health in a low-income country like Brazil, helping to identify the particularities of parenting in this context. Thereby, this study aimed to investigate symptoms of common mental disorders (CMD) in Brazilian parents during the COVID-19 pandemic and its associated factors.

\section{Methods}

\section{Design and Procedures}

This was a cross-sectional correlational study, according to Johnson's (2001) criteria, which was developed as part of the project entitled "Parental mental health and use of digital media by young children: a comparative study before and during the COVID-19 pandemic". The project was approved by the National Research Ethics Commission, CAAE Protocol No 30809520.9.0000.5334. For this study, only data obtained during the pandemic were used.

Participants were invited via social networks and researchers' personal contacts. Before the survey, there was a Free and Informed Consent Form presenting the procedures and purpose of the study as well as participants' rights. All participants gave their consent and responded to an online survey. Data collection was conducted from May 27 to June 15, 2020.

\section{Participants}

The study sample consisted of 232 Brazilian parents ranging from 20 to 48 years old $(M=33.85$; $\mathrm{SD}=4.83)$ with healthy children aged $1-36$ months $(M=17.00$; $\mathrm{SD}=9,87)$. Participants were primarily mothers $(91.8 \%)$ and $55.6 \%$ of children were girls. Most participants were from the south $(71.9 \%)$ and southeast $(15.5 \%)$ regions of Brazil, the others were from northeast $(10 \%)$, middle west $(1.8 \%)$ and north $(0.8 \%)$ regions.

\section{Instruments}

\section{Sociodemographic Questionnaire}

This instrument was used to access sociodemographic data such as age, educational level, income and aspects related to the context of the pandemic such as changes in income and in the way work is carried out, loss of social support in child care, contact with people in the COVID-19 high-risk group, among others.
Self-Reporting Questionnaire (SRQ-20)_Brazilian

Portuguese version (Mari \& Williams, 1986)

This is a psychiatric screening tool proposed by Harding et al. (1980) and developed by the World Health Organization for non-psychotic mental disorders, especially for symptoms of depression and anxiety, and can be used in clinical and non-clinical populations. The questionnaire consists of 20 yes/no questions: four are about physical symptoms and 16 about psycho-emotional disorders. Each affirmative answer is scored as 1 and the final score is given by the total sum. The cut-off point is eight for the clinical group (Mari \& Williams, 1986). The Brazilian version of the SRQ-20 used was validated by Mari and Williams (1986) and reassessed by Gonçalves et al. (2008). The internal consistency of the Brazilian version was $\alpha=0.86$ (Gonçalves et al., 2008). The instrument was used in this research to collect information about parental mental health.

\section{Perceived Stress Scale (PSS-4)_Brazilian Portuguese version (Faro, 2015)}

This instrument is widely used to detect the degree to which individuals evaluate situations and/or stimuli in their experiential context as stressors (Cohen et al., 1983). The PSS is originally composed of 14 items, but there are reduced versions with 10 and 4 items. Faro (2015) performed the PSS Confirmatory Factor Analysis (CFA) in the Brazilian context in a population sample testing the three versions. The two-factor model proved to be superior in all versions. The PSS-4, version used in this study, showed excellent indicators in the CFA, despite the Cronbach's Alpha of 0.64. This value, although below the cutoff point usually considered, may be related to the lower variability of the distribution produced by the low number of items, which does not necessarily compromise internal validity (Faro, 2015). In this study, the Cronbach's Alpha of PSS was 0.80 which is a value considered satisfactory (Nunnally, 1978). The PSS author indicates the version of four items preferably for epidemiological research with the aim of conducting a general stress screening.

Parenting Sense of Competence Scale (PSOC)_Brazilian Portuguese version (Pardo et al., 2018)

This instrument, originally developed by Gibaud-Wallston and Wandersman (1978), assesses the perception of competence of fathers and mothers in their parenting functions. The scale consists of 16 items that vary on a scale of 1-6 points between "totally disagree" and "totally agree". The sum of the items generates a score that indicates the perception of competence, which is understood as 16-31: very 
weak; 32-47: weak; 48-64 average; 65-80: strong; 81-96: very strong. The original PSOC was adapted for Brazilian Portuguese and evidence-based on the internal structure of the instrument showed satisfactory values for the twofactor solution $(\chi 2 / \mathrm{gl}=1.188 ; \mathrm{CFI}=0.970 ; \mathrm{RMSEA}=$ 0.035; pRSMEA = 0.703). The internal consistency in this sample was $\alpha=0.812$, indicating satisfactory reliability (Nunnally, 1978).

\section{Data Analysis}

The data was analyzed using the Statistical Package for the Social Sciences (SPSS) version 24 software. Descriptive statistics (frequencies, means, and standard deviations) of the variables were calculated and the distribution patterns were inspected. As the variables showed only a slight skewness and kurtosis (values $<1$ ), parametric tests were used. Initially, chi-square tests were performed among CMD symptoms and variables such as being in social distance, time in confinement, child's gender, decreased income due to the pandemic, number of children, occupation, being in the COVID-19 risk group, living with someone who is in the risk group or having someone close in the risk group, but who does not live together.

Thereafter, Pearson's correlations were conducted between continuous variables: CMD symptoms, family income, child's age, perceived stress, parental sense of competence, and perceived loss of social support. The variables correlated with the CMD symptoms (dependent variable) were selected as independent variables in the multiple linear regression model. The following parameters were inspected in the regression models and the Enter method was used: independence of residues, homoscedasticity, and error distribution pattern to verify the adequacy of the analysis. For the linear model, regression weights $(\beta)$ and the percentage of explained variance $\left(R^{2}\right.$ adj) were reported to interpret the results. The level of significance adopted was $5 \%$.

\section{Results}

At the time of data collection, $88.8 \%$ of parents were in social distancing, of which $69.4 \%$ were carrying out work and/or study activities at home. $82.8 \%$ reported being in this situation for more than two months. Most parents are middle class and highly educated (Table 1) and $56.5 \%$ declared that their family income had decreased due to pandemic. In that period, the minimum wage in Brazil was USD 190.18 per month (BRL 1037.00). Most families had only one child $(74.6 \%)$ and three people depending on the family income $(62.5 \%)$; and most participants lived with a partner $(92.7 \%)$.
Regarding the tested variables, $14.2 \%$ of the sample claimed to be in COVID-19 high-risk group (self-reported diabetes, high blood pressure, over 60 years of age, cardiac or breathing problems). As for contact with people in this high-risk group, $19.8 \%$ said they lived with someone in the risk group and $65.9 \%$ reported having someone close in the risk group, but who does not live together.

Concerning the time spent with the child during social distancing, $45.7 \%$ stated that they spend all day with the child and $47.4 \%$ that they spend most of the day with the child, sharing with another caregiver. One-quarter of participants reported receiving educational assignments from their children's daycare centers. As for support for children's care, parents reported the loss of help from daycare centers $(49.1 \%)$, family and friends $(47.4 \%)$, and nannies (12.9\%). Only $19.8 \%$ did not have any of these types of support before the pandemic.

The mean score on SRQ-20 was $7.22(\mathrm{SD}=4.28)$ and $46.6 \%$ of the sample was above the cutoff point for CMD. In chi-square tests, CMD symptoms were positively associated with being in social distancing $(\chi 2=9.360$, df $=3$, $p=0.025)$, with time in confinement $(\chi 2=9.127, \mathrm{df}=3$, $p=0.028$ ), with being in COVID-19 risk group $(\chi 2=4.513, \mathrm{df}=1, p=0.034)$ and with living with someone who is in the risk group $(\chi 2=6.272$, $\mathrm{df}=1$, $p=0.012)$. Occupation, decreased income due to the pandemic, child's gender, number of children, and having someone close in the risk group but who does not live together were not associated with CMD symptoms.

In respect to the perceived stress, the mean score of the sample was $11.7(\mathrm{SD}=2.94)$ and $92.2 \%$ of the sample was above the cutoff point (8) for high stress. With regard to the parental sense of competence, the mean score was 72.3 $(\mathrm{SD}=9.77)$ which indicated a strong sense of competence. The other selected variable was family income $(M=5.27$; $\mathrm{SD}=1.64)$. In this sample, the mean income was around six to nine minimum wages. These variables were tested in Pearson's correlations with CMD symptoms.

The CMD symptoms correlated with most variables (Table 2). It is observed that as parents present more levels of perceived stress, they also present more CMD symptoms. In this sense, the higher is the family income, and the sense of parental competence, the fewer fathers and mothers present CMD symptoms. No correlation was found between CMD symptoms, child's age, and perceived loss of social support. The variables showed magnitude between weak to strong $r=-0.25$ to $r=0.70(p<0.01)$. All variables that displayed significant correlations were entered into the regression.

Table 3 shows the multiple linear regression model for the CMD symptoms, in which the independent variables were those that showed correlation with the dependent variable. In this model, the variable Perceived Stress 
Table 1 Family income and educational level $(N=232)$

\begin{tabular}{lrr}
\hline & $f^{a}$ & $\%$ \\
\hline Monthly family income & & \\
$\leq 1$ minimum wage & $7.0 \%$ \\
$1-3$ minimum wages & 22 & $9.5 \%$ \\
$3-6$ minimum wages & 59 & $25.4 \%$ \\
$6-9$ minimum wages & 48 & $20.7 \%$ \\
$9-12$ minimum wages & 39 & $16.8 \%$ \\
$12-15$ minimum wages & 24 & $10.3 \%$ \\
$\geq 15$ minimum wages & 33 & $14.2 \%$ \\
Educational level & & $1.7 \%$ \\
Up to elementary school & 4 & $15.5 \%$ \\
High school & 36 & $28.9 \%$ \\
Undergraduate school & 67 & $1.3 \%$ \\
Associate degree & 3 & $52.6 \%$ \\
Graduate school & 122 & \\
\hline
\end{tabular}

Table 2 Mean (SD) and correlations among the variables

\begin{tabular}{|c|c|c|c|c|c|c|c|}
\hline & $\mathrm{M}(\mathrm{SD})$ & 1 & 2 & 3 & 4 & 5 & 6 \\
\hline 1. Symptoms of CMD & $7.22(4.28)$ & 1 & $-.25 * *$ & .01 & $.70 * *$ & $-.37 * *$ & .08 \\
\hline 2. Family income & $5.27(1.64)$ & & 1 & -.00 & $-.22 * *$ & .04 & .12 \\
\hline 3. Child's age & $17.0(9.87)$ & & & 1 & -.02 & -.02 & $.29 * *$ \\
\hline 4. Perceived stress & $11.7(2.94)$ & & & & 1 & $-.38 * *$ & .09 \\
\hline 5. Parental sense of competence & $72.3(9.77)$ & & & & & 1 & -.05 \\
\hline 6. Perceived loss of social support & $1.09(0.72)$ & & & & & & 1 \\
\hline
\end{tabular}

${ }^{*} p<.05, * * p<.001$

Table 3 Symptoms of CMD

\begin{tabular}{lrrrr}
\hline Variable & \multicolumn{1}{c}{$B$} & $95 \%$ IC & $\beta$ & $t$ \\
\hline Constant & 2.230 & {$[-2.284 ; 6.744]$} & .973 & .331 \\
Family income & -.284 & {$[-.531 ;-.038]$} & -.109 & -2.28 \\
Perceived stress & .901 & {$[.753 ; 1.050]$} & .618 & .024 \\
Parental sense of competence & -.057 & {$[-.101 ;-.013]$} & -.130 & .001 \\
\hline
\end{tabular}

Durbin-Watson $=2.03 ; R^{2}$ adj-0.495 $(N=232, p<0.001)$

( $\beta=0.618)$ showed a stronger association with the CMD symptoms, followed by the variable Parental Sense of Competence $(\beta=-0.130)$. Thus, perceived stress is positively associated with CMD symptoms, while higher family income and parental sense of competence can decrease the possibility of presenting the outcome. The model proved to be satisfactory, with an Adjusted $R$ Square value of $49.5 \%$.

\section{Discussion}

This cross-sectional study found a relatively high prevalence of CMD symptoms (46.6\%) among parents. Pre pandemic adult cohorts in Brazil reported CMD prevalences ranging from $14.7 \%$ (Moraes et al., 2017) to $28 \%$ (Anselmi et al., 2008) and up to $37.6 \%$ among an urban sample of 1095 low-income mothers in Brazil (Carmo 
et al., 2018). This high prevalence is still lower than that found in the present study. Epidemiological studies conducted during the pandemic also found elevated rates of depression, anxiety, and stress among adults. Of the 799 Brazilian adults assessed by Duarte et al. (2020) 40,9\% screened positive for CMD symptoms. Chinese parents of hospitalized children accessed after the outbreak had significantly worse depression and anxiety scores when compared to parents of hospitalized children accessed before this event (Yuan et al., 2020). These data suggest that the COVID-19 pandemic may have an association with the risk of mental health problems across populations.

Perceived stress was the most related variable to parents' symptoms of CMD, showing a positive association. Surprisingly, $92.2 \%$ of the sample screened positive for high levels of stress. Although the general population is experiencing considerable stress related to the coronavirus and reporting higher levels of stress than in recent years (APA, 2020a), parents can be more affected by this situation: they presented significantly higher rates of stress-related to COVID-19 when compared to adults without children (APA, 2020b).

Due to COVID-19 pandemic and social distance measures, parents may have increased preoccupations and many changes to deal with, such as fear of being infected or of loved ones being infected, loss of support network, new challenges like homeschooling and home office and cope with children's feelings. It may be possible that the child's demands and parent's concerns about protecting children from the infection cause parents to be distressed, impacting their mental health. Additionally, the agespecific demands of babies and toddlers may increase parents' stress as suggested by Bai et al., (2020) findings.

A quarter of our sample also had to deal with educational assignments provided by children's daycare centers. Studies have shown that online/distance learning can become a burden for parents (APA, 2020a; Brom et al., 2020). This is a controversial alternative for babies and toddlers, as the process of learning in early childhood education happens through interactions and playing as established by Brazil's National Model Curriculum for Early Childhood Education (Brasil, 1998). The limited autonomy and concentration capacity in this developmental stage demand greater availability from parents to make the educational activities feasible. At the same time, virtual meetings with the teacher and peers have been recommended as a way to maintain social ties during the quarantine (Brasil, 2020b). These meetings are also intended to support parents since most of them had a significant loss of social support due to social distance measures.

Although attending to distance measures is until this moment one of the most effective ways to contain the virus, the results of the present study showed that being confined at home was associated with higher levels of CMD among parents. An evidence review (Brooks et al., 2020) pointed out that psychological impacts of quarantine include frustration, boredom, inadequate supplies, inadequate information, financial loss, and stigma and those stressors seem to be intensified by longer quarantine duration. In our study, as well, a longer time in confinement was associated with CMD symptoms. Brazil's Ministry of Health (Brasil, 2020c) has already warned that increased length of stay and contact within the household during the COVID-19 pandemic can leave parents overwhelmed and distressed, especially in crowded homes. In situations where quarantine is deemed necessary, officials should provide a clear rationale for quarantine, information about protocols, and ensure sufficient supplies are provided (Brooks et al., 2020) to minimize its effects.

Consistent with previous studies (Duarte et al., 2020; Qiu et al., 2020), being part of the risk group for COVID19 disease was positively associated with CMD. The increased risk of presenting the infection in its aggravated form possibly makes those parents distressed. Furthermore, they may be afraid of getting infected because they have children whose care depends on them. Results also showed positive associations between CMD and living with someone that belongs to the risk group, suggesting that in addition to concerns about their own health, parents may also be distressed of people close to them getting contaminated. A recent American study (APA, 2020a) found that getting coronavirus and a family member getting coronavirus were both parental sources of stress.

The results of the present study showed that parents' symptoms of CMD were negatively associated with family income. Low socioeconomic status (SES) is a well-known risk factor for mental health problems (Hudson, 2005; van der Waerden et al., 2014). The relationship between low SES and CMD is a relevant concern in a country of high social inequality such as Brazil. The economic impacts of the pandemic pose additional concerns as to how Brazilian's mental health will be affected and how officials will address this matter during and after the outbreak. Families from low SES may be the most affected and therefore need to be urgently targeted in both economic and health-related policies.

Contrary to our expectations and results from previous studies (Duarte et al., 2020; Lebel et al., 2020; Wu et al., 2020), experiencing a decrease in family income and loss of support in childcare caused by the pandemic were not associated with CMD symptoms. A hypothesis for that is the medium-high income accessed families may have more means to maintain the quality of life and share household tasks, despite the changes in childcare and family income. These parents may also have jobs that are more flexible to be adapted to home office demands. Indeed, almost half of 
the respondents $(47,4 \%)$ reported sharing children's care with another person even with the maintenance of social isolation. These may not be the case for more vulnerable families and single parents. Even so, parents reported a significant loss of support in childcare during the coronavirus pandemic $(49.1 \%$ lost the daycare center and $47.4 \%$ lost the support of family and friends) suggesting an accumulation of tasks.

On the other hand, for some families quarantine may have created an opportunity for mothers and fathers to spend more quality time with their children. An American survey found that $68 \%$ of fathers reported feeling closer or much closer to their children since the pandemic (Weissbourd et al., 2020). In another study, $82 \%$ of the parents said they were grateful for the additional time they have had with their child during the pandemic (APA, 2020b). This strengthened relationship could buffer the effect of more negative changes but more research is needed to support this hypothesis.

Notably, our results showed that perceived parental competence was negatively associated with symptoms of CMD. Previous studies found that a lower perception of parental competence was associated with higher levels of depression (Chung et al., 2018) and parental stress (Löfgren et al., 2017). A study carried out during the Zika virus epidemic in Brazil found that parental self-efficacy predicted better levels of general health and was a mediator of the relationship between life satisfaction, negative affections, and maternal mental health (Lima \& Souza, 2019). It is possible that feeling competent as a parent may protect them from mental suffering. Thereby, interventions targeting parental competence should be considered to address the mental health impacts of the COVID-19 pandemic and to prevent problems both in parents and children.

As observed in previous studies (Bai et al., 2020; Duarte et al., 2020; Johnson et al., 2020; Wang et al., 2020) the mental health impacts of the COVID-19 pandemic seem to be gender-related. Compared to fathers, mothers who lived in Chinese urban areas had a higher risk of poor mental health outcomes, possibly related to the overlap of care and work activities (Bai et al., 2020). Brazilian women had almost three times the chance of presenting CMD symptoms than men during the COVID-19 pandemic (Duarte et al., 2020). Due to cultural expectations, women are traditionally who take care of families and who probably will be responsible for childcare and household tasks during confinement (Alon et al., 2020). The high prevalence of CMD symptoms and perceived stress found in the current study may be related to the high representation of women in our sample ( $91.8 \%$ of mothers). At the same time, fathers' reduced participation in research leaves the impact of the COVID-19 pandemic on their mental health underrepresented, making it harder to understand how they can be better supported.

In this sense, it is noteworthy that our sample is not representative of all Brazilian parents. Respondents are mostly high income and well-educated mothers from the South region of the country, known for good health indicators. One reason for that lack of representativeness is the use of online data collection. As pointed out by Hunter (2012) online surveys may not reach socioeconomic variability, since many people have restricted access to technology. Anyhow, face-to-face interviews are not possible to be carried out at the moment for sanitary reasons and online data collection is a vital alternative. It is relevant to acknowledge that vulnerable families' experiences in the context of the COVID-19 pandemic may not be visible in research (Brom et al., 2020). For that reason, future studies should extend the sample representativeness, including a larger number of fathers and a wider socioeconomic diversity, also accessing participants from several Brazilian states and minority groups.

Despite those limitations, the current findings have important implications for health policies in response to the COVID-19 crisis. Mental health interventions need to consider low-income parents that are in confinement for long periods and should target stress reduction and parental sense of competence. Parents have to deal with specific challenges such as the accumulation of tasks and worries about their family safety besides their own. Parents' mental health should be a concern due to its relevance to early interactions and impact on child development. That's even more significant in a period of social isolation, when family members are the only source of care and support for babies and toddlers.

\section{Conclusion}

The current study investigated factors associated with common mental disorders (CMD) symptoms in a sample of Brazilian parents of children up to three years old during the COVID-19 pandemic. Results showed relatively high CMD scores, especially among parents confined for a longer period, and those belonging to the risk group, or living with someone who did. CMD symptoms were negatively associated with parental sense of competence and positively associated with perceived stress. Experiencing a decrease in family income and loss of support in childcare were not associated with CMD symptoms. A negative association between CMD and family income was found, which is a cause of concern in Brazil, a country of high socioeconomic inequality. The COVID-19 pandemic tends to leave such discrepancies even more evident and to make vulnerable people more prone to suffer from CMD. 
Despite these results, this study does not allow inferring causality, since it is a cross-sectional study. Data of mental health status previous to the pandemic were not considered. However, the results were compared to other studies with similar samples that used the same instrument to access CMD symptoms. Another limitation was the non-use of a pandemic-specific mental health instrument, as this study was carried out at a time when there were still no instruments with adequate psychometric properties for that context (Cortez et al., 2020). In this way, a constructspecific and widely used instrument that allows comparison with other studies was chosen.

Future studies could access a wider socioeconomic diversity, including also particularly vulnerable groups. Regarding the applications of this study, interventions targeting parental competence and stress reduction should be considered to address the mental health impacts of the pandemic. Caring for parents' mental health is a way of promoting children's development potential and should be a concern in the context of the COVID-19 pandemic. Early childhood policies need to assist adults who take care of children, strengthening social investment, and supporting families to exercise healthy parenting.

Authors Contribution All the authors contributed to the data collection. HSR and MLA assisted with the data analyses and wrote the paper. GV, FMM, BGP and MYM wrote the paper. MAMP and GBF contributed by critically reviewing the content and text revision.

Funding Not applicable.

Data Availability The datasets used and/or analyzed during the current study are available from the corresponding author on reasonable request.

Code Availability Not applicable.

\section{Declarations}

Conflicts of interest The authors declare that they have no competing interests.

Consent to Participate Informed consent was obtained from all individual participants included in the study.

Consent for Publication All authors read and approved the final manuscript for its publication.

Ethics Approval All procedures performed in studies involving human participants were in accordance with the ethical standards of the institutional and national research committee. This project was approved by an Ethics Commitee (CAEE number: 30809520.9.0000.5334).

\section{References}

Alon, T. M., Doepke, M., Olmstead-Rumsey, J., \& Tertilt, M. (2020). The impact of COVID-19 on gender equality. National Bureau of Economic Research. https://doi.org/10.3386/w26947

American Psychological Association. (2020a). Stress in the time of COVID-19. Volume One. https://www.apa.org/news/press/rele ases/stress/2020/stress-in-america-covid.pdf

American Psychological Association. (2020b). Stress in the time of COVID-19. Volume Two. https://www.apa.org/news/pre ss/releases/stress/2020/stress-in-america-covid-june.pdf

Anselmi, L., Barros, F. C., Minten, G. C., Gigante, D. P., Horta, B. L., \& Victora, C. G. (2008). Prevalence and early determinants of common mental disorders in the 1982 birth cohort, Pelotas Southern Brazil. Revista De Saúde Pública, 42(Suppl. 2), 26-33. https://doi.org/10.1590/S0034-89102008000900005

Bai, R., Wang, Z., Liang, J., Qi, J., \& He, X. (in press). The effect of the COVID-19 outbreak on children's behavior and parents' mental health in China: A research study. Research Square, 1-21. https://doi.org/10.21203/rs.3.rs-22686/v1

Bao, Y., Sun, Y., Meng, S., Shi, J., \& Lu, L. (2020). 2019-nCoV epidemic: Address mental health care to empower society. The Lancet, 395(10224), e37-e38. https://doi.org/10.1016/S0140-67 36(20)30309-3

Bartlett, J. D., Griffin, J., \& Thomson, D. (2020). Resources for supporting children's emotional well-being during the COVID19 pandemic. Retrieved July 15, 2020, from https://www. childtrends.org/publications/resources-for-supporting-childrensemotional-well-being-during-the-covid-19-pandemic

Bowlby, J. (1989). Uma base segura: aplicações clínicas da teoria do apego. [Secure Base: Parent-Child Attachment and Healthy Human Development]. Porto Alegre: Artes Médicas.

Brasil. (1998). Referenciais Curriculares Nacionais para a Educação Infantil [A National Model Curriculum for Early Childhood Education]. http://portal.mec.gov.br/seb/arquivos/pdf/volume3.pdf

Brasil. (2020a). Painel Coronavírus. [Coronavirus' Panel] Retrieved from https://covid.saude.gov.br/

Brasil. (2020b). Opinião do Conselho Nacional de Educação Número 5/2020, aprovado em 20 de abril, 2020 [National Education Council Opinion Number 5/2020, approved on April 28, 2020]. Retrieved from http://portal.mec.gov.br/index.php?option=com_docman\&vi ew=download\&alias=145011-pcp005-20\&category_slug=marco2020-pdf\&Itemid=30192

Brasil. (2020c). Crianças na pandemia COVID-19. Saúde mental e atenção psicossocial na pandemia COVID-19. [Children in the COVID-19 pandemic. Mental health and psychosocial care in the COVID-19 pandemic] https://www.fiocruzbrasilia.fio cruz.br/wpcontent/uploads/2020/05/crianc\%cc\%a7as_pandem ia.pdf

Brom C., Lukavský J., Greger, D., Hannemann, T., Straková, J., \& Švař́čcek, R. (2020). Mandatory home education during the COVID-19 lockdown in the Czech Republic: A rapid survey of 1st-9th graders' parents. Frontiers in Education, 5, 103. https://doi.org/10.3389/feduc.2020.00103

Brooks, S. K., Webster, R. K., Smith, L. E., Woodland, L., Wessely, S., Greenberg, N., \& Rubin, G. J. (2020). The psychological impact of quarantine and how to reduce it: Rapid review of the evidence. The Lancet, 395(10227), 912-920. https://doi.org/10.1 016/S0140-6736(20)30460-8

Carmo, M. B. B., Santos, L. M., Feitosa, C. A., Fiaccone, R. L., Silva, N. B., Santos, D. N., Barreto, M. L., \& Amorim, L. D. (2018). Screening for common mental disorders using the SRQ-20 in Brazil: What are the alternative strategies for analysis? Brazilian Journal of Psychiatry, 40(2), 115-122. https://doi.org/10.15 90/1516-4446-2016-2139 
Center on the Developing Child at Harvard University. (2017). Three principles to improve outcomes for children and families. Retrieved July 20, 2020, from http://www.devel opingchild.harvard.edu

Cluver, L., Lachman, J. M., Sherr, L., Wessels, I., Krug, E., Rakotomalala, S., \& McDonald, K. (2020). Parenting in a time of COVID-19. The Lancet, 395(10231), e64. https://doi. org/10.1016/S0140-6736(20)30736-4

Chung, F. F., Wan, G. H., Kuo, S. C., Lin, K. C., \& Liu, H. E. (2018). Mother-infant interaction quality and sense of parenting competence at six months postpartum for first-time mothers in Taiwan: A multiple time-series designs. BMC Pregnancy and Childbirth. https://doi.org/10.1186/s12884-018-1979-7

Chung, G., Lanier, P., \& Wong, P. Y. J. (2020). Mediating effects of parental stress on harsh parenting and parent-child relationship during coronavirus (COVID-19) pandemic in Singapore. Journal of Family Violence. https://doi.org/10.1007/s10896-020-00200-1

Cohen, S., Kamarck, T., \& Mermelstein, R. (1983). A global measure of perceived stress. Journal of Health and Social Behavior, 24, 385-396. https://doi.org/10.2307/2136404

Cortez, P. A., Joseph, S. J., Das, N., Bhandari, S. S., \& Shoib, S. (2020). Tools to measure the psychological impact of the COVID-19 pandemic: What do we have in the platter? Asian Journal of Psychiatry, 53, 102371. https://doi.org/10.1016/j.a jp.2020.102371

Dekovic, M., Asscher, J. J., Hermanns, J., Reitz, E., Prinzie, P., \& van den Akker, A. L. (2010). Tracing changes in families who participated in the home-start parenting program: Parental sense of competence as mechanism of change. Prevention Science, 11(3), 263-274. https://doi.org/10.1007/s11121-009-0166-5

Duarte, M. Q., Santo, M. A. S., Lima, C. P., Giordani, J. P., \& Trentini, C. M. (2020). COVID-19 e os impactos na saúde mental: uma amostra do Rio Grande do Sul, Brasil. Ciência \& Saúde Coletiva, 25(9), 3401-3412. https://doi.org/10.1590/14 13-81232020259.16472020

Faro, A. (2015). Confirmatory factor analysis of three versions of the perceived stress scale (PSS): A population-based study. Psicologia: Reflexão e Crítica, 28(1), 21-30.

Ferreira, B., Monteiro, L., Fernandes, C., Cardoso, J., Veríssimo, M., \& Santos, A. J. (2014). Percepção de competência parental: Exploração de domínio geral de competência e domínios específicos de auto-eficácia, numa amostra de pais e mães portuguesas. Análise Psicológica, 32(2), 145-156. https://doi. org/10.14417/ap. 854

Gibaud-Wallston, J., \& Wandersman, L. P. (1978). Development and utility of the parenting sense of competence scale. The annual meeting of the American Psychological Association.

Gonçalves, D. M., Stein, A. T., \& Kapczinski, F. (2008). Performance of the self-reporting questionnaire as a psychiatric screening questionnaire: A comparative study with Structured Clinical Interview for DSM-IV-TR. Cadernos De Saúde Pública, 24(2), 380-390. https://doi.org/10.1590/S0102-311X2008000200017

Harding, T. W., Arango, M. V., Baltazar, J., Climent, C. E., Ibrahim, H. H. A., Ignacio, L. L., Murthy, R. S., \& Wig, N. N. (1980). Mental disorders in primary health care: A study of their frequency and diagnosis in four developing countries. Psychological Medicine, 10, 231-241.

Holly, L. E., Fenley, A. R., Kritikos, T. K., Merson, R. A., Abidin, R. R., \& Langer, D. A. (2019). Evidence-base update for parenting stress measures in clinical samples. Journal of Clinical Child \& Adolescent Psychology, 48(5), 685-705. https://doi.org/10.10 80/15374416.2019.1639515

Holmes, E. A., O’Connor, R. C., Perry, V. H., Tracey, I., Wessely, S., Arseneault, L., \& Bullmore, E. (2020). Multidisciplinary research priorities for the COVID-19 pandemic: A call for action for mental health science. Lancet Psychiatry, 7, 547-560. https://doi.org/10.1016/S2215-0366(20)30168-1

Hudson, C. G. (2005). Socioeconomic status and mental illness: Tests of the social causation and selection hypotheses. American Journal of Orthopsychiatry, 75(1), 3-18. https://doi.org/ 10.1037/0002-9432.75.1.3

Hunter, L. (2012). Challenging the reported disadvantages of e-questionnaires and addressing methodological issues of online data collection. Nurse Researcher, 20(1), 11-20. https://doi.org/10.7748/nr2012.09.20.1.11.c9303

Johnson, R. (2001). Toward a new classification of nonexperimental quantitative research. Educational Researcher, 30, 3-13. https://doi.org/10.3102/0013189X030002003

Johnson, M. C., Saletti-Cuesta, L., \& Tumas, N. (2020). Emotions, concerns and reflections regarding the COVID-19 pandemic in Argentina. Ciência \& Saúde Coletiva, 25(1), 2447-2456. https://doi.org/10.1590/1413-81232020256.1.10472020

Kingston, D., \& Tough, S. (2014). Prenatal and postnatal maternal mental health and school-age child development: A systematic review. Maternal and Child Health Journal, 18(7), 1728-1741. https://doi.org/10.1007/s10995-013-1418-3

Laifer, L. M., Blackburn, A. M., Goetter, E. M., Ohye, B. Y., Simon, N. M., \& Bui, E. (2019). Potential mediating role of parenting competence in the relationship between posttraumatic stress disorder and family functioning post-9/11 veteran parents. Journal of Child and Family Studies, 28(7), 1843-1849. https://doi.org/10.1007/s10826-019-01405-9

Lebel, C., MacKinnon, A., Bagshawe, M., Tomfohr-Madsen, L., \& Giesbrecht, G. (2020). Elevated depression and anxiety symptoms among pregnant individuals during the COVID-19 pandemic. Journal of affective disorders, 277, 5-13. https://doi.org/ 10.1016/j.jad.2020.07.126

Lima, T. J. S., \& Souza, L. (2019). The role of parental self-efficacy in the mental health of mothers of children with Congenital Zika Syndrome. Ciência \& Saúde Coletiva. Retrieved July 15, 2020, from http://www.cienciaesaudecoletiva.com.br/artigos/o-pap el-da-autoeficacia-parental-na-saude-mental-de-maes-de-crian cas-com-sindrome-da-zika-congenita/ 17246 ? $\mathrm{id}=17246 \& \mathrm{id}=17246 \& \mathrm{id}=17246$

Löfgren, H. O., Petersen, S., Nilsson, K., Ghazinour, M., \& Hägglöf, B. (2017). Effects of parent training programmes on parents' sense of competence in a general population sample. Global Journal of Health Science, 9(7), 24. https://doi.org/ 10.5539/gjhs.v9n7p24

Mari, J. J., \& Williams, P. (1986). A validity study of a psychiatric screening questionnaire (SRQ-20) in primary care in the city of São Paulo. British Journal of Psychiatry, 148(1), 23-26. https://doi.org/10.1192/bjp.148.1.23

Matias, M., Ferreira, T., Vieira, J., Cadima, J., Leal, T., \& Mena Matos, P. (2017). Workplace family Support, parental satisfaction, and work-family conflict: Individual and crossover effects among dual-earner couples. Applied Psychology, 66(4), 628-652. https://doi.org/10.1111/apps.12103

Moraes, R. S. M., Silva, D. A. S., Oliveira, W. F., \& Peres, M. A (2017). Social inequalities in the prevalence of common mental disorders in adults: A population-based study in Southern Brazil. Revista Brasileira De Epidemiologia, 20(1), 43-56. https://doi.org/10.1590/1980-5497201700010004

Nunes, C., \& Ayala Nunes, L. (2016). Parenting sense of competence in at psychosocial tisk families and child well-being. Bordón. Revista de Pedagogía. https://doi.org/10.13042/Bordon.20 16.48589

Nunnally, J. C. (1978). Psychometric Theory (2nd ed.). McGraw Hill. Ornell, F., Schuch, J. B., Sordi, A. O., \& Kessler, F. H. P. (2020). "Pandemic fear" and COVID-19: Mental health burden and 
strategies. Brazilian Journal of Psychiatry, 42(3), 232-235. https://doi.org/10.1590/1516-4446-2020-0008

Pardo, M. B. L., Carvalho, M. S. B., Fontaine, A. M., \& Freitas, D. F. (2018). Parenting sense of competence: A study of the psychometric properties of the scale with a brazilian sample. Avaliação Psicológica, 17(2), 243-251. https://doi.org/10.15689/ap.20 18.1702.14426.10

Parfitt, Y., Pike, A., \& Ayers, S. (2013). The impact of parents' mental health on parent-baby interaction: A prospective study. Infant Behavior and Development, 36(4), 599-608. https://doi.org/10.1016/j.infbeh.2013.06.003

Qiu, J., Shen, B., Zhao, M., Wang, Z., Xie, B., \& Yifeng, X. (2020). A nationwide survey of psychological distress among chinese people in the COVID-19 epidemic: Implications and policy recommendations. General Psychiatry, 33, e100213. https://doi.org/10.1136/gpsych-2020-100213

Stern, D. N. (1997). A constelação da maternidade: o panorama da psicoterapia pais/bebê. [The motherhood constellation] Porto Alegre: Artes Médicas.

Taylor, M. R., Agho, K. E., Stevens, G. J., \& Raphael, B. (2008). Factors influencing psychological distress during a disease epidemic: Data from Australia's first outbreak equine influenza. BMC Public Health. https://doi.org/10.1186/1471-2458-8-347

Tristão, R. M., Neiva, E. R., Barnes, C. R., \& Adamson-Macedo, E. (2015). Validation of the scale of perceived self-efficacy of maternal parenting in brazilian sample. Journal of Human Growth and Development, 25(3), 277. https://doi.org/10.73 22/jhgd.96759

van der Waerden, J. E., Hoefnagels, C., Hosman, C. M., \& Jansen, M. W. (2014). Defining subgroups of low socioeconomic status women at risk for depressive symptoms: The importance of perceived stress and cumulative risks. International Journal of Social Psychiatry, 60(8), 772-782. https://doi.org/10.1177/002 0764014522751

Wang, C., Pan, R., Wan, X., Tan, Y., Xu, L., Ho, C. S., \& Ho, R. C. (2020). Immediate psychological responses and associated factors during the initial stage of the 2019 coronavirus disease (COVID-19) epidemic among the general population in China. International Journal of Environmental Research and Public Health, 17(5), 1729. https://doi.org/10.3390/ijerph17051729

Weaver, M. S., \& Wiener, L. (2020). Applying palliative care principles to communicate with children about COVID-19.
Journal of Pain and Symptom Management, 60(1), 8-11. https://doi.org/10.1016/j.jpainsymman.2020.03.020

Weissbourd, R., Batanova, M., McIntyre, J., \& Torres, E. (2020, July 15). How the pandemic is strengthening fathers' relationships with their children. Retrieved from https://mcc.gse.harvard.edu/

Winnicott, D. W. (2006). Os bebês e suas mães. [Babies and their mothers]. São Paulo: Martins Fontes. (Original published in 1987).

World Health Organization. (2020a). Statement on the second meeting of the International Health Regulations (2005) Emergency Committee regarding the outbreak of novel Coronavirus (2019-nCoV). Retrieved July 15, 2020, from https://www. who.int/news-room/detail/30-01-2020-statement-on-the-secondmeeting-of-the-international-health-regulations-(2005)-emerge ncy-committee-regarding-the-outbreak-of-novel-coronavirus(2019-ncov)

World Health Organization. (2020b). Coronavirus disease 2019 (COVID-19): situation report, 195. Retrieved August 02, 2020, from https://www.who.int/docs/default-source/coronaviruse/situ ation-reports/20200802-covid-19-sitrep-195.pdf?sfvrsn=5e 5da0c5_2

Wu, Y., Zhang, C., Liu, H., Duan, C., Li, C., Jianxia Fan, J., \& Huang, H. (2020). Perinatal depression of women along with 2019 novel Coronavirus breakout in China. SSRN Electronic Journal. https://doi.org/10.2139/ssrn.3539359

Yuan, R., Xu, Q. H., Xia, C. C., Lou, C. Y., Xie, Z., Ge, Q. M., \& Shao, Y. (2020). Psychological status of parents of hospitalized children during the COVID-19 epidemic in China. Psychiatry Research, 288, 112953 https://doi.org/10.1016/j.psychres.20 20.112953

Zhang, J., Wu, W., Zhao, X., \& Zhang, W. (2020). Recommended psychological crisis intervention response to the 2019 novel coronavirus pneumonia outbreak in China: A model of West China Hospital. Precision Clinical Medicine, 3(1), 3-8. https://doi.org/10.1093/pcmedi/pbaa006

Publisher's Note Springer Nature remains neutral with regard to jurisdictional claims in published maps and institutional affiliations. 